\title{
Análise da usinagem na recuperação por soldagem do pescoço do cilindro de laminação de ferro fundido
}

\author{
Machining analysis in the recovery by welding of the cast iron rolling mill roll neck
}

Análisis de mecanizado en la recuperación por soldadura de cuello de cilindro de laminación de fundición

\section{Resumo}

Cilindros de laminação são utilizados na conformação de chapas, barras, perfis etc. Alguns cilindros quando fundidos, recebem algum tipo de tratamento térmico em seguida são usinados e inspecionados em que se pode verificar não conformidades ou erros dimensionais durante o processo de usinagem. Esses defeitos são constatados diante de um laudo em auditorias, que dependendo pode ser recuperado via solda e em seguida foi retrabalhado em um torno CNC. Após os processos de soldagem SMAW e usinagem o cilindro passa por um rigoroso processo de inspeção para garantir o controle da qualidade, já que pode ser somado dois processos tribológicos importantes no processo de fabricação duplicando ou combinando defeitos internos e superficiais. Os procedimentos da pesquisa comparativas adotadas foram a prática laboratoriais metalográficas dos cavacos gerados, utilizando do ensaio de dureza nas regiões da zona termicamente afetada ZTA e metal base MB. Os resultados dos procedimentos de recuperação apresentaram uma combinação entre análises do processo de soldagem SMAW e análise dos cavacos da usinagem por torneamento da região recuperada. Verificou-se diferenças nas regiões usinadas dos cavacos em termo de tipo e forma de cavacos, além das mudanças morfológicas das grafitas. Os cavacos apresentados na região da ZTA apresentaram-se como de materiais cisalhantes para frágeis e na região do metal de base como cavaco de material cisalhante. As grafitas mudaram por conta da temperatura de resfriamento do processo de soldagem pelo calor gerado na usinagem, combinado. A proposta do trabalho pode levar a confirmação da ligação entre as áreas de soldagem e usinagem e sua relação com o controle de qualidade de inspeção.

Palavras-chave: Laminação; Processo de soldagem por eletrodo revestido; Usinagem; Ferros fundidos; Cavacos.

\section{Abstract}

Rolling rolls are used in forming sheets, bars, profiles, etc. Some cylinders, when cast, receive some type of heat treatment, then they are machined and inspected in which non-conformities or dimensional errors can be verified during the machining process. These defects are verified in the face of an audit report, which depending on can be 
recovered via welding and then reworked on a CNC lathe. After the SMAW welding and machining processes, the cylinder undergoes a rigorous inspection process to ensure quality control, as two important tribological processes can be added to the manufacturing process by duplicating or combining internal and surface defects. The comparative research procedures adopted were the metallographic laboratory practice of the generated chips, using the hardness test in the regions of the heat-affected zone ZTA and base metal MB. The results of the recovery procedures showed a combination of analysis of the SMAW welding process and analysis of the chips from turning machining of the recovered region. Differences were verified in the machined regions of the chips in terms of type and shape of chips, in addition to the morphological changes of the graphites. The chips presented in the HAZ region were presented as shear to brittle materials and in the base metal region as a shear material chip. Graphites have changed due to the cooling temperature of the welding process by the heat generated in machining, combined. The work proposal can lead to confirmation of the link between the welding and machining areas and its relationship with inspection quality control.

Keywords: Lamination; Coated electrode welding process; Machining; Cast iron; Chips.

\section{Resumen}

Los rodillos de laminación se utilizan para formar láminas, barras, perfiles, etc. Algunos cilindros al ser fundidos reciben algún tipo de tratamiento térmico, luego son maquinados e inspeccionados en los cuales se pueden verificar las no conformidades o errores dimensionales durante el proceso de maquinado. Estos defectos se verifican frente a un informe de auditoría, que dependiendo de se pueden recuperar mediante soldadura y luego volver a trabajar en un torno CNC. Después de los procesos de soldadura y mecanizado SMAW, el cilindro se somete a un riguroso proceso de inspección para garantizar el control de calidad, ya que se pueden agregar dos procesos tribológicos importantes al proceso de fabricación al duplicar o combinar defectos internos y superficiales. Los procedimientos de investigación comparativa adoptados fueron la práctica de laboratorio metalográfico de las virutas generadas, utilizando la prueba de dureza en las regiones de la zona afectada por el calor ZTA y el metal base MB. Los resultados de los procedimientos de recuperación mostraron una combinación de análisis del proceso de soldadura SMAW y análisis de las virutas del mecanizado de torneado de la región recuperada. Se verificaron diferencias en las regiones maquinadas de las virutas en cuanto al tipo y forma de las virutas, además de los cambios morfológicos de los grafitos. Las virutas presentadas en la región HAZ se presentaron como materiales frágiles al corte y en la región del metal base como virutas de material cortante. Los grafitos han cambiado debido a la temperatura de enfriamiento del proceso de soldadura por el calor generado en el mecanizado combinado. La propuesta de trabajo puede conducir a la confirmación del vínculo entre las áreas de soldadura y mecanizado y su relación con el control de calidad de inspección.

Palabras clave: Laminación; Proceso de soldadura de electrodos revestidos; Maquinado; Hierro Fundido; Virutas.

\section{Introdução}

Segundo Askeland et al., (2008), conhecer as propriedades mecânicas dos materiais de pesquisa e compreender seus fundamentos e aplicações podem auxiliar os desenvolvedores nos projetos de engenharia. Uma maneira de obter as propriedades mecânicas de um material é realizar ensaios mecânicos em laboratório. Que consistem basicamente em submeter a uma amostra do material um carregamento conhecido e analisar a resposta e o comportamento do elemento nessa situação.

Os ferros fundidos são ligas metálicas ferrosas que apresentam a mais elevada produção, em termos de peso, para a fabricação de peças fundidas no mundo. São ligas que oferecem grandes vantagens durante o processamento, pois sua composição química, próxima da eutética, leva a uma temperatura de fusão mais baixa. Comparadas ao aço, são ligas que apresentam custo mais baixo de fabricação (Andrade, 2009).

Para Chegatti (2004), o processo de fabricação dos ferros fundidos tem como objetivo a fusão de metais, que em estado líquido, são vazados ou despejados em um molde contendo uma cavidade na geometria desejada para a peça final. Os processos podem se constituir de dois tipos de operações, as que tem por finalidade produzir o molde e as que tem o objetivo de fundir o metal.

Nas ligas ferro-carbono, os ferros fundidos constituem um grupo de ligas de importância fundamental para a indústria, pois com a introdução de elementos de liga e a aplicação de tratamentos térmicos adequados, tornou-se possível o emprego do ferro fundido em aplicações antes exclusivas dos aços (Chiaverini, 1990). 
Segundo Li (2018), o ferro fundido nodular desempenha um papel significativo em muitos campos da indústria, tais como motores em navios, máquina ferramenta, tubulação de pressão e válvulas industriais. Esses ferros fundidos são compostos principalmente de grafite, perlita e ferrita. O nódulo foi composto de grafite foi geralmente cercado por ferrita para formar uma estrutura chamada de "olho bovino".

De acordo com Cajocaru, et. al., (2019), na produção de ferro fundido dúctil, uma base de ferro fundido, controlado por meio da composição química $(\mathrm{C}, \mathrm{Si}, \mathrm{Mn}, \mathrm{P}, \mathrm{S}$, elementos com pouca concentração), está sujeito a tratamento de modularização (usualmente com a utilização de magnésio, com ou sem contribuição de elementos de terra raras). O resultado principal consiste na formação em grafita nodular, mais ou menos similar a uma forma esférica. Usualmente, a estrutura tratada com magnésio inclui grafita nodular, leva uma qualidade morfológica inferior para com a forma esférica e ainda baixa quantidade, enquanto carbetos livres estão usualmente presentes. Para os autores adicionar elementos inoculantes, tais como, $\mathrm{C}, \mathrm{Ba}, \mathrm{Sr}, \mathrm{Zr}, \mathrm{Ce}, \mathrm{La}$, etc, depois de tratar com magnésio pode favorecer melhor a formação dessa estrutura característica de grafitas nodulares ou esféricas, ajudando a moldar esse nome de "ferro fundido dúctil".

Para Sirisak (2018), o ferro fundido cinzento ou ferro de grafite em veias tem muitas aplicações industriais devido à sua excelente capacidade de fundição e usinabilidade. A excelente usinabilidade desse material tem sido estudada e demonstrada por muitas décadas.

Os ferros fundidos cinzentos apresentam grafitas em forma de veias. Na metalografia ótica a grafita aparece como partículas isoladas, constituindo, por fim, um esqueleto contínuo em cada célula eutética. A matriz pode ser ferrítica ou mais comumente perlítica. Os ferros fundidos cinzentos cobrem uma faixa de limite de resistência de 100MPa (mais comumente de 150 a 300MPa), sendo que o alongamento por ser muito pequeno não foi especificado.

A grafita em forma de veias fornece ainda bons valores de condutividade térmica, o que torna o ferro fundido cinzento um material muito empregado para componentes sujeitos a fadiga térmica (tambores e discos de freio, cabeçotes de motor). Em discos e tambores de freio utilizam-se ferros fundidos cinzentos com alto teor de carbono para diminuir a temperatura de trabalho, o que resulta em menores taxas de desgaste tanto para o disco para as pastilhas. (Guesser, 2009)

Para Telles (2007), existem vários tipos de ferro fundido, cada um com características bem distintas, tais como ferro fundido cinzento, branco, nodular e vermicular. $\mathrm{O}$ ferro fundido cinzento apresenta como elementos de liga fundamentais o carbono e o silício. Ele foi considerado um aliga ternária de ferro-carbono-silício. Uma parcela relativamente grande do carbono está no estado livre (grafita lamelar) e outra parcela no estado combinado o carbeto de ferrro (cementita). O ferro fundido cinzento foi um dos materiais de melhor fundibilidade em que pode apresentar uma das mais baixas temperaturas de fusão dentre as ligas ferrosas. Sua contração na passagem líquida para sólido foi baixa, favorecendo a obtenção de peças com poucos defeitos internos. Para a maioria das aplicações pode ser utilizado no estado bruto de solidificação. O ferro fundido branco apresenta como elementos de liga fundamentais o carbono e o silício. Devido às condições de fabricação e menor teor de silício, apresenta o carbono quase inteiramente na forma combinada.

Para Solimani (2011), a laminação foi o processo de conformação mecânica que consiste em deformar o metal pela sua passagem entre dois cilindros paralelos girando em sentidos opostos, com a mesma velocidade inicial. FOI um processo que apresenta alta produtividade e um controle dimensional do produto acabado que pode ser bastante preciso. Podem apresentar geratriz retilínea (laminação de produtos planos) ou canais entalhados em diferentes formatos (laminação de produtos não planos). Os cilindros são componentes de grande destaque na fabricação dos laminados, mantendo contato direto com o produto acabado e sendo responsável por dar sua forma e aspecto.

Os cilindros de laminação são sempre constituídos de duas estruturas, a casca, que correspondem que m que a 30\% do todo e tem como principais características a resistência ao desgaste e o núcleo, fabricado para apresentar elevadas resistências à flexão e torção corresponde a 70\% do todo. Essas duas estruturas, casca e núcleo, são obtidos por meio de materiais diferentes, 
do resfriamento diferenciado ou do processo de fabricação adequado para cada região. A flexão ocorre devido às altas cargas de laminação aplicadas nas extremidades dos cilindros de encosto que por sua vez são transmitidas para os cilindros de trabalho (Solimani, 2011).

Segundo Diniz (2013), durante o processo de usinagem foi necessário entender o comportamento de fenômenos ou parâmetros ligados ao processo tribológico ferramenta, material e forças de usinagem, tais como desgaste da ferramenta, aresta postiça de corte, calor gerado, velocidade de corte, avanço, profundidade de corte, etc., e para se obter cientificamente uma explicação para o comportamento desses fatores pode ser necessário um estudo minucioso do processo de formação dos cavacos.

De acordo com Saad (2012), para se obter boa qualidade na produção de ferros fundidos, é necessário submete-los por variados testes e assim eliminar possíveis danos futuros ao segmento do produto. Seguindo essa linha de pensamento, segue abaixo alguns exemplos de testes e ensaios aplicados ao ferros fundidos: Ensaio químico; Ensaio metalográfico; Ensaio de tração; Radiografia; Teste de som por leve impacto; Teste de impacto; Teste de pressão; Teste de penetração; Teste de ultrassom.

\section{Metodologia}

Este estudo adotou como procedimento metodológico a utilização de pesquisa aplicada, exploratória e análise comparativa.

Barros e Lehfeld (2000, p. 78), explica que a pesquisa aplicada tem como motivação a necessidade de produzir conhecimento para aplicação de seus resultados, com o objetivo de "contribuir para fins práticos, visando à solução mais ou menos imediata do problema encontrado na realidade".

De acordo com Nunan (1997), uma pesquisa aplicada apresenta: a) fundamentação teórica; b) metodologia de pesquisa; c) Análise e discussão dos dados. Neste caso, a fundamentação teórica serve, entre outras possibilidades, de referencial para a análise dos dados, dados estes que foram coletados por meio de uma metodologia.

Segundo Gil (2002), a pesquisa exploratória tem por objetivo aprimorar hipóteses, validar instrumentos e proporcionar familiaridade com o campo de estudo. Constitui a primeira etapa de um estudo mais amplo, e é muito utilizada em pesquisas cujo tema foi pouco explorado, podendo ser aplicada em estudos iniciais para se obter uma visão geral acerca de determinados fatos.

Os procedimentos da pesquisa comparativas adotadas foram a prática laboratoriais metalográficas dos cavacos gerados, utilizando do ensaio de dureza nas regiões da zona termicamente afetada ZTA e metal base MB.

\subsection{Materiais e Métodos}

Os cilindros de laminação, durante a usinagem, podem apresentar problemas no processo de torneamento muito pelos defeitos ou erros de fundição como poros ou trincas, quando isso ocorre, um laudo deve ser emitido. Quando o cilindro apresenta trincas pode ser necessária uma usinagem de rebaixamento que não comprometa o seu uso.

A peça rebaixada por essa usinagem sob o aspecto de controle de especificação normativa da empresa passa para próxima etapa de recuperação o processo SMAW de soldagem, depois desta soldagem deve ser usinado a região recuperada. Nesse mesmo processo de soldagem, podem ser reparadas as irregularidades que implicam na redução máxima de uma porcentagem aceitável da área existente, desde que não se encontrem nas regiões críticas do cilindro, como por exemplo: mesa, raios de concordância (mesa/pescoço) e nos assentos de mancais. 
A soldagem dos cilindros de ferro fundido foi feita a 'frio', ou seja, sem pré-aquecimento devido ao tamanho dos cilindros. Por isso para conseguir uma zona de fusão mole, a soldagem e feita em vários passes. Nesse processo o objetivo principal foi manter a peça o mais frio possível, sendo necessário interromper as soldas em intervalos para permitir que a peça esfrie. A principal razão para manter a temperatura baixa foi impedir o empenamento ou a ruptura passível do aquecimento e de expansões desiguais. A contração do material depositado quando passa do estado fundido para o sólido foi maior do que a do ferro fundido. Consequentemente, quando o material fundido de um eletrodo foi depositado no ferro fundido, contrai mais do que o ferro fundido. Essa contração diferencial pode causar tensão residual no material da solda e no ferro fundido.

Para minimizar as tensões foi feito o martelamento do metal depositado da solda antes que tenha a possibilidade de se resfriar e contrair. Isto causa o estiramento do metal da solda diminuindo a distorção e equilibrando assim sua redução de área natural, Figura 1.

Figura 1 - Recuperação por solda e a inspeção da região recuperada.

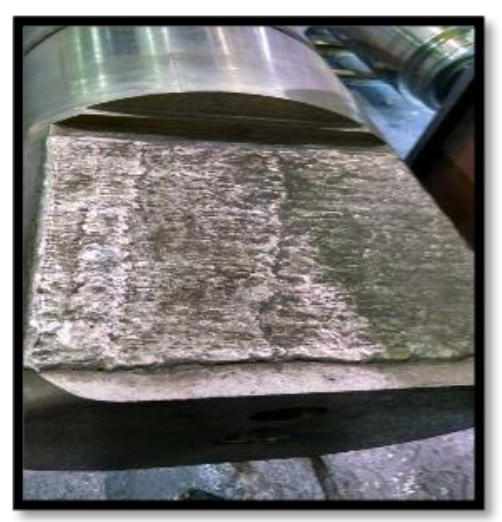

Fonte: Autores (2021).

Na Figura 2, ilustra um outro exemplo de reparo no pescoço do cilindro de ferro fundido de coquilhamento indefinido que também foi feito pelo processo Shielded Metal Arc Welding - SMAW ou eletrodo revestido. Nesta ocasião, o cilindro estava com problemas dimensional em um dos canais do pescoço inferior.

Figura 2 - Recuperação por solda - Shielded Metal Arc Welding - SMAW.

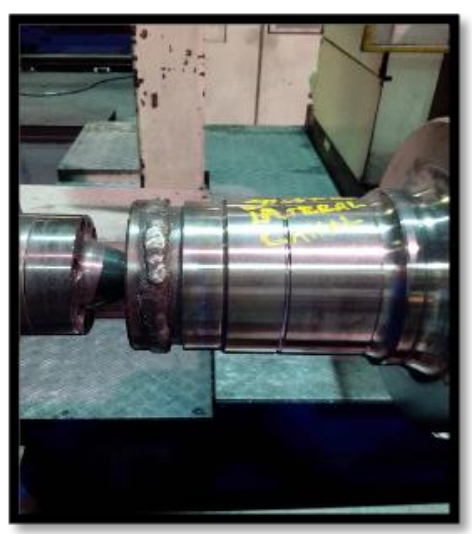

Fonte: Autores (2021).

$\mathrm{Na}$ etapa da usinagem foi realizada novamente o torneamento do cilindro e por meio da Figura 3 foi possível visualizar a usinagem da região da solda para a etapa de retirada do excesso de solda e os cavacos (na parte de baixo da imagem) das regiões do metal base e Zona Termicamente Afetada - ZTA, em que foi coletado as amostras de cavaco. 
Figura 3 - Usinagem da região soldada para a retirada do excesso do cavaco.

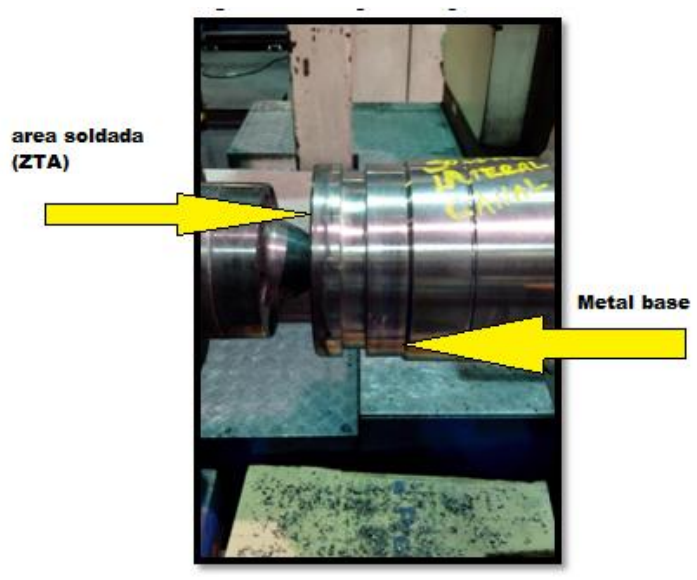

Fonte: Autores (2021).

Foram realizadas as análises para a caracterização microestrutural (metalografia, dureza, MEV, EDS) nos laboratórios da Faculdade de Tecnologia do Estado de São Paulo, Unidade de Pindamonhangaba e na Escola de Engenharia de Lorena Universidade de São Paulo.

Os procedimentos experimentais basearam-se nos seguintes passos: escolha de um cilindro de ferro fundido de coquilhamento indefinido, obtenção de amostras de metal base, ZTA e a área soldada do cilindro. Para o processo metalográfico foi utilizado a politriz (Selvyt Marrom de $6 \mu \mathrm{m}$ e Velvet Vermelho de $1 \mu \mathrm{m}$ ) para as análises microscópicas foi utilizado o microscópio óptico (Olympus SZ2-ET 6,7 a 45X e Olympus BX51M 1000X) e o Microscópio Eletrônico de Varredura (Léo VP 1450). Para as análises dimensionais foi utilizado o micrômetro (Mitutoyo 0-300mm/0,001). No processo de soldagem foi utilizado o eletrodo $\mathrm{NiFeCu}$, específico para soldagem de ferros fundidos e para medida de dureza um instrumento para teste de dureza em metais, EQUOTIP 3.

Para a revelar dos microconstituintes foram utilizados três reagentes químicos com diferentes composições, devido à dificuldade no processo de ataque químico em diferentes materiais e comportamento da superfície. Os reagentes utilizados então foram Nital 2\%, Picral 3,5\% e Marble 3,5\%. O ataque foi interrompido com água e o processo de secagem foi feito pela evaporação do álcool etílico absoluto, auxiliado por jato de ar quente. Foi utilizado o microscópio óptico com magnificação de 500x para análise das fases e a morfologia microestrutural. Para o processo de recuperação por SMAW utilizado foram utilizados as condições e parâmetros de soldagem, Tabela 1.

Tabela 1 - Parâmetros do eletro e condições de soldagem.

\begin{tabular}{lll}
\hline Empresa & Norma & Tamanho (mm) \\
\hline NCS & AWS/ASME/DIN & $3,25 X 350$ \\
Composição & Especificação & Polaridade \\
$\mathrm{NiFeCl}$ & $60 \mathrm{Ni}-\mathrm{SFA} 5.14$ AD-07 & CC+/CA \\
Lote & Peso Kg & Amperagem (A) \\
$\mathrm{C} 2018290182$ & 5 & $80-50$ \\
\hline
\end{tabular}

Fonte: Autores (2021).

Com relação a ferramenta no processo de usinagem, observa-se uma típica ferramenta de cerâmica de alumina CA, da classe K, para aços e ferro fundidos, de face única, sem quebra cavaco e para acabamento em "V" com ângulo de inclinação de cinco graus, para torneamento longitudinal de código VBGW160408, Figura 4. 
Figura 4 - Ferramenta de corte usada durante o estudo para as atividades experimentais no processo de usinagem.

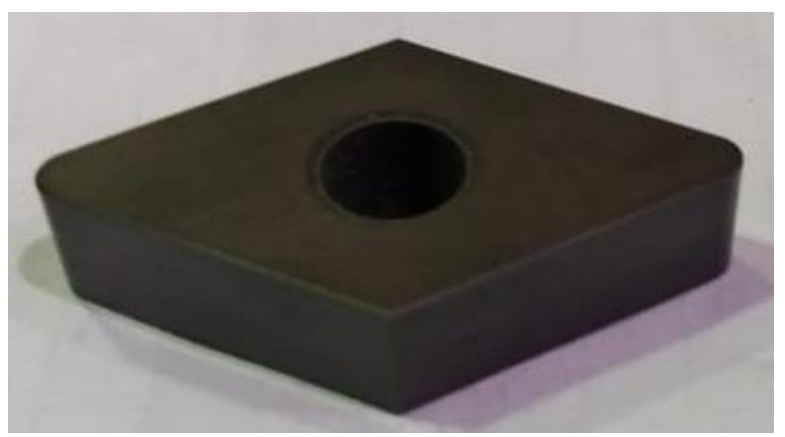

Fonte: Autores (2021).

A ferramenta de corte demonstrada na Figura 4, tem as especificações ideais para aços e ferro fundidos.

\section{Resultados e Discussão}

As análises microscópicas propostas por meio os ataques com Nital e Picral não foi possível devido à falta de clareza (nitidez), isso deve ter ocorrido devido à alta dureza do ferro fundido coquilhado.

Neste sentido optou-se pelo reagente "Marble" de composição $(4 \mathrm{~g} \mathrm{CuSO} 2+20 \mathrm{~mL} \mathrm{HCl}+20 \mathrm{~mL} \mathrm{H} 2 \mathrm{O})$, prática por imersão, que por sua vez foi capaz de revelar as amostras. Pode-se perceber em primeira mão por meio da análise microscópica do cilindro, presença de dendrítas de cementita e perlita escura, observou-se ainda ledeburita transformada entre as dendrítas sendo composta por cementita e glóbulos escuros de grafita, Figura 5.

Para ajudar a entender melhor essas observações pode então existir uma relação com o processo de obtenção de ligas de ferros fundido industriais em que a mudança da microestrutura tem significante influência no comportamento da resistência e nos processos de fabricação por usinagem e soldagem, o autor Tooptong et. al. (2018) descreve em seu trabalho um resumo da influência do resfriamento e dos elementos de ligas, segundo ele quando o ferro fundido foi solidificado abaixo da temperatura eutectóide em uma condição industrial típica, fases de austenita e grafita podem ser formadas. Dependendo dos elementos (por exemplo, $\mathrm{Mn}$ ou $\mathrm{Mg}$ ) presentes no ferro em solução, formam-se as distintas morfologias da fase de grafita, que são classificadas em veias, nódulos ou "vermes". 
Figuras 5 (5a), (5b), (5c), (5d) e (5e) - Micrografias óptica do metal de base do cilindro de ferro fundido de coquilhamento indefinido com ampliações de 50x, 100x, 200x, 500x e 1000x atacada, respectivamente.

(5a)

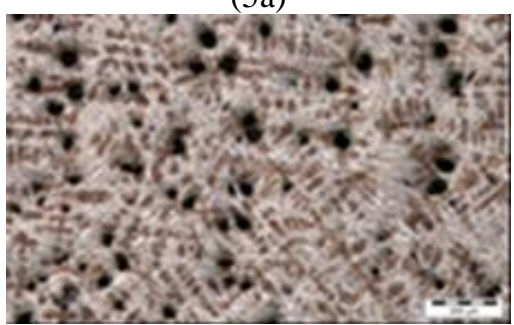

$(5 c)$

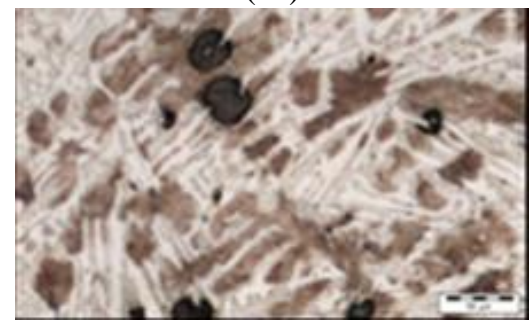

(5b)

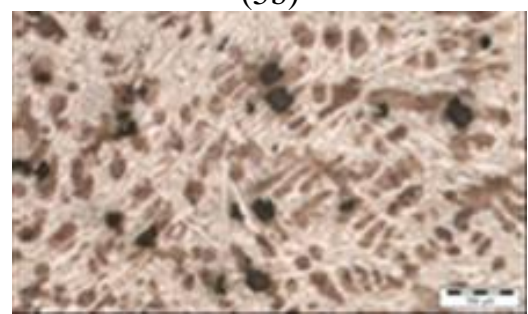

$(5 \mathrm{~d})$

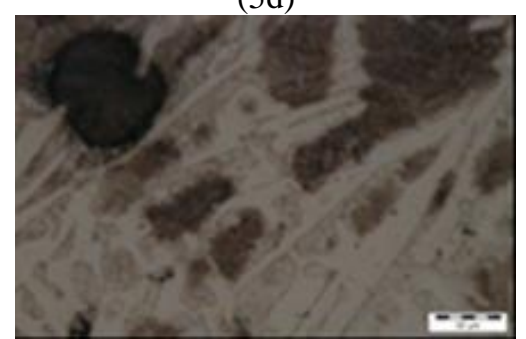

$(5 \mathrm{e})$

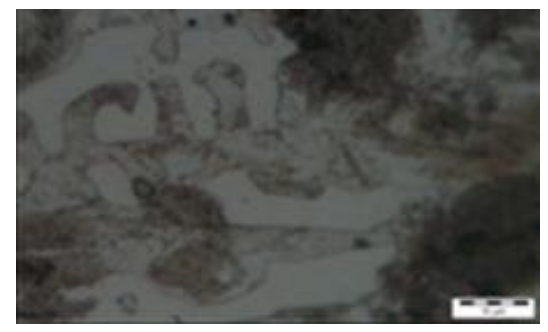

Fonte: Autores (2021).

No entanto, quando o molde foi resfriado abaixo da temperatura eutetóide a austenita se torna fase perlítica, consistindo de camadas alternadas de ferrita e cementita. O ferro fundido acaba se tornando a fase de grafita e perlita. Além disso, cada ferro fundido possui outros elementos em traços distintos, como $\mathrm{Si}, \mathrm{Mn}, \mathrm{Al}, \mathrm{Cr}, \mathrm{Ti}, \mathrm{Mg}, \mathrm{Mo}, \mathrm{V}$ e Ni, que afetam a temperatura e microestrutura resultante. Cada elemento influencia em certos aspectos do processo de fundição, como já discutido o Si foi usado para aumentar a grafitização, enquanto o Mn foi adicionado ao banho formando MnS e o Mg favorece a formação das grafitas nodulares presentes nessas mesmas micrografias, Figura 5.

A região da zona termicamente afetadas ZTA, percebeu-se a matriz austenítica, com presença de perlita, sobretudo há a presença de uma baixa fração de dendrítas, e diferentemente do metal de base revelou-se grafitas tipo "E" atreladas a grafitas em nódulos, esses veios têm como presença característica em ferro fundidos cinzentos, Figuras 6.d e 6.e.

Estas características morfológicas podem ser explicadas com o processo de soldagem diante do resfriamento não controlado e lento, pois se tratava de uma peça de geometria grande em que pode favorecer a formação do ferro fundido cinzento. Esse resfriamento lento e a presença do silício no material pode favorecer a formação da austenita e grafita em forma de veios. Isso pode levar a uma análise de que provavelmente essa região ficara com um aspecto de transição de ferro fundido coquilhado com ainda presença de nódulos de grafita e cementita para ferro fundido cinzento. 
Research, Society and Development, v. 11, n. 3, e20011326091, 2022

(CC BY 4.0) | ISSN 2525-3409 | DOI: http://dx.doi.org/10.33448/rsd-v11i3.26091

Figuras 6 (6a), (6b), (6c), (6d) e (6e) - Micrografia da ZTA do cilindro de ferro fundido de coquilhamento indefinido soldado pelo processo SMAW com ampliações de 50x, 100x, 200x, 500x e 1000x, respectivamente.

(6a)

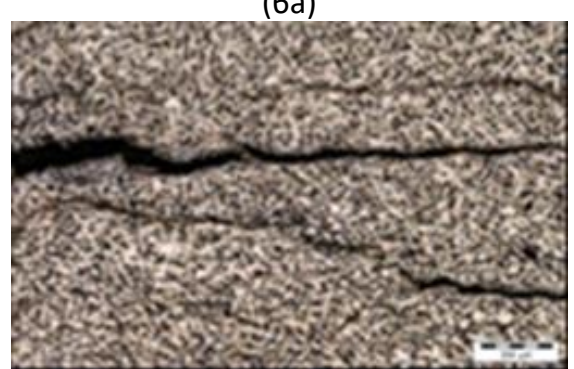

(6d) (6b)

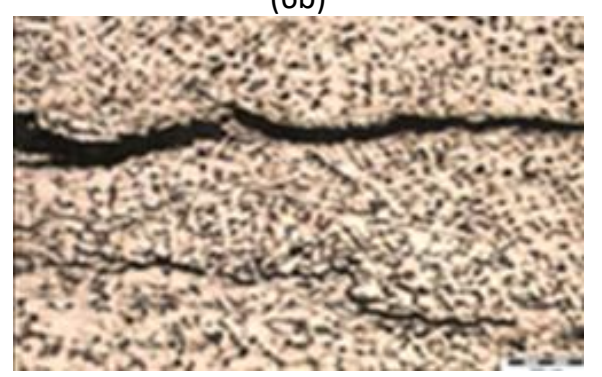

(6c)

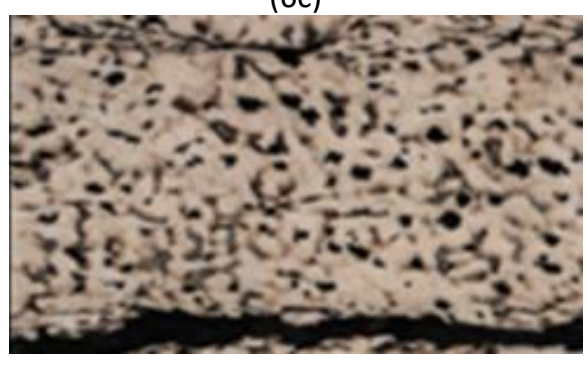

(6e)
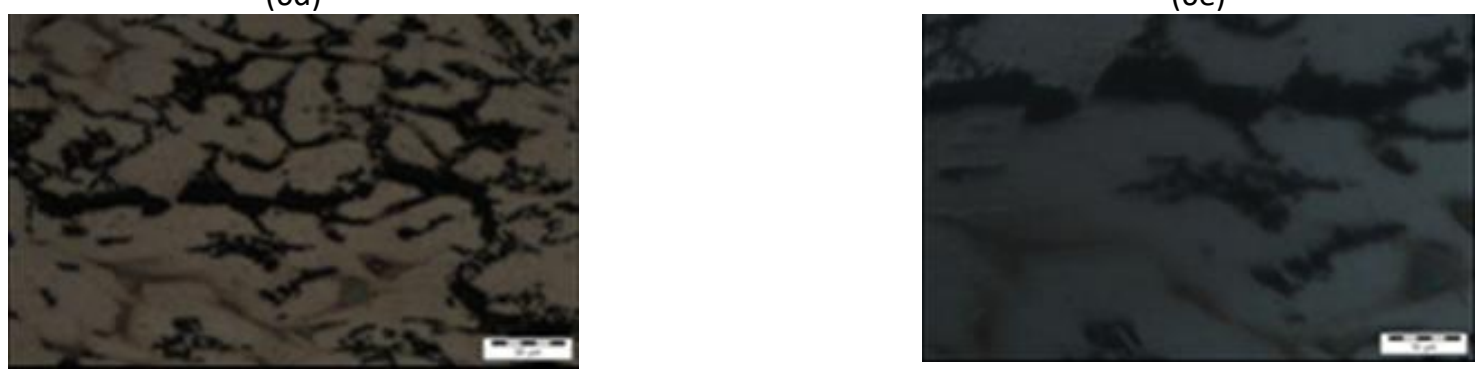

Fonte: Autores (2021).

As micrografias eletrônicas de varredura, demostram a zona fundido do pescoço recuperado pelo eletrodo a base de níquel. Normalmente usa-se este tipo de eletrodo para soldar os ferros fundidos, às vezes, ele foi utilizado como "almofada" ou "amanteigamento" das ligas de ferros fundidos, Figuras 7 (a), (b) e (c).

$\mathrm{O}$ níquel em pequenas proporções diminui a profundidade da coquilhamento, apesar de representar um quarto do efeito do silício, além disso teores acima entre 4 a 5\% ele diminui esse efeito e pode ser acompanhado com aumento da dureza. O níquel quando foi adicionado acima desses valores volta a atuar como elemento gamagênico diminuindo a dureza do ferro fundido.

Nas micrografias observa-se uma matriz austenítica com elemento de grafita tipo "IV" e classe "A", norma ASTM A 247, Figuras 7 (a), (b) e (c).

Figura 7 (a), (b) e (c) - Micrografias Eletrônicas de varredura da Zona Fundida (ZF) da região recuperada.
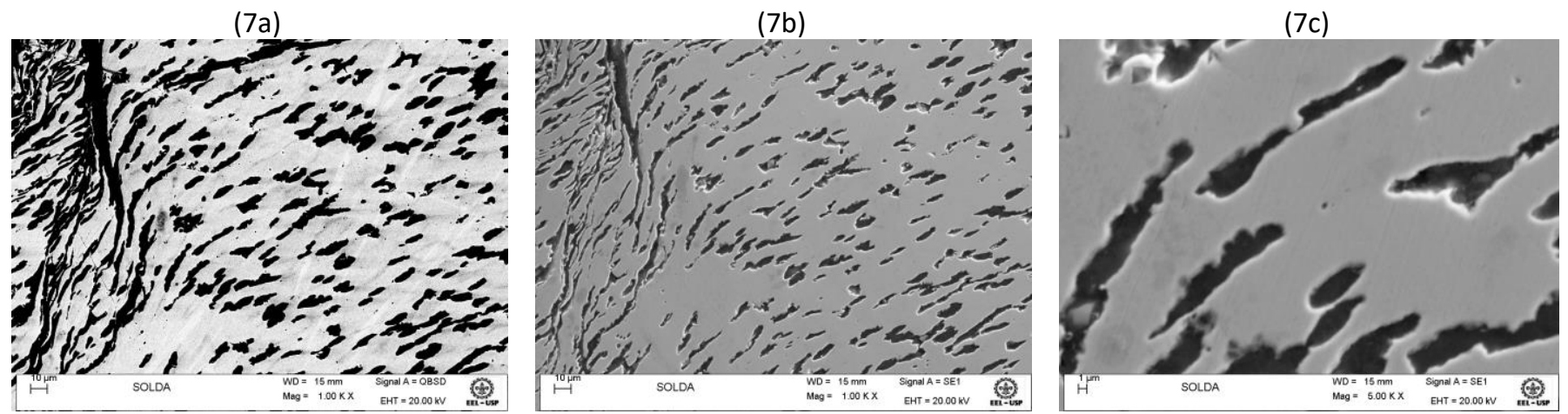

Fonte: Autores (2021). 
Os cavacos apresentados nas micrografias ópticas (Figura 8) são as seguintes regiões (a) da zona fundida e (b) da região termicamente afetada que evidenciam morfologias do tipo cisalhante na área fundida e fragmentadas ou lascas pelo efeito térmico (Ramon et. al, 2020).

Os cavacos da forma cisalhante têm um aspecto de "serra" na parte interna devido a resistência a deformação do material perante a pressão específica de corte provocado pela ferramenta, ou seja, típico de materiais de dureza intermediária. No entanto, não se prolonga sua sequência de formação, quebrando-se de forma sequencial no mecanismo de sua formação.

Destaca-se na área termicamente afetada apresenta diversidades em relação ao tipo e forma de cavaco e em particular não verificou o aspecto de encurvamento semelhante a micrografia Figura 8 (a). Evidencia geometria com maior fragmentação que colabora com a hipótese do comportamento de material frágil, devido ao aumento da dureza na região típicas de zonas termicamente afetadas, Tabela 2.

Figura 8 (a) e (b) - Micrografia Eletrônica de Varredura de Cavacos obtidos pelo processo de recuperação via soldagem.

(8a) Morfologia e Topografia do cavaco da zona fundida

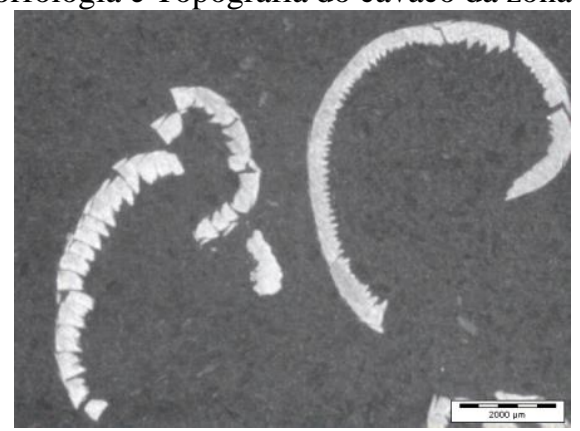

(8b) Morfologia e Topografia do cavaco na ZTA

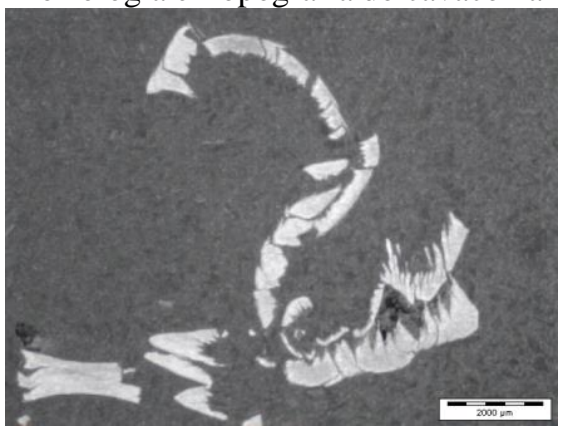

Fonte: Autores (2021).

Para o detalhamento do entendimento da influência dos processos térmicos e da usinagem nos cavacos e sua diversidade morfológica e topográfica com o auxílio da ampliação, a forma geométrica da região da ZTA, ficou mais fracionada, isso pelo aumento da resistência das tensões cisalhantes e encruamento dinâmico, isso se deve aos materiais como os ferros fundidos pois possuem dificuldades em se deformar ocorrendo o endurecimento de forma dinâmica, devido a baixas energias de deformação que contribui para que os cavacos sofram fissuras em suas áreas de superfícies internas.

Nota se na região ZTA, a redução dos elementos grafites típicos dos ferros fundidos cinzentos do cavaco. A diminuição da influência dos componentes grafitizantes como níquel e silício que durante o resfriamento rápido junto a outra parte do material de base dos cilindros de laminação. Em contrapartida, considera-se com relação ao resfriamento é fato de não se dar tempo do carbono se difundir pela austenita, precipita-se e ora combina-se com o ferro formando os carbetos de ferro não solúveis na posterior ferrita, criando um sistema metaestável perlítico. Quanto menor a quantidade de grafita mais o ferro fundido cinzento aproxima do ferro fundido branco, pois seu carbono vai sendo combinado com o ferro (Dawson, 1994; Guesser et al, 2001).

Observa-se por meio das micrografias ópticas (Figuras 9 (d) e (f)), mudanças morfológicas das grafitas desses cavacos, neste caso, além de diminuir a fração destas grafitas mostram-se mais "afinados" e alongados, ficando fora das classificações ou talvez mais parecida com a "tipo A" uniforme e aleatória, essa forma geométrica traduz mudanças pelo momento da usinagem (Klink et. Al, 2001). 
A geometria da grafita traz comportamento de desgaste nos processos de fabricação e aplicação, assim sendo, elementos com características geométricas mais circulares ou esféricas podem reduzir os desgastes na hora de usinar, ou seja, pode-se comportar como elementos deslizantes ou lubrificantes (Guesser et. al, 2005).

O ensaio de dureza Rockwell C foi realizado com o intuito de verificar as diferenças de dureza das regiões do MB e ZTA, em que foi realizado o reparo com o processo de soldagem SMAW, neste sentido fazer analogias entre as análises das morfologias dos cavacos (Heisser et. Al., 2003).

Figuras 9 - (a), (b), (c), (d), (e) e (f) - Micrografias dos cavacos polidos nas regiões de solda e ZTA.

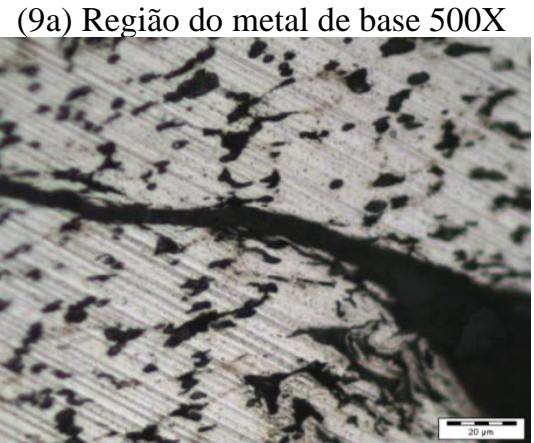

(9d) Região da ZTA, 100X

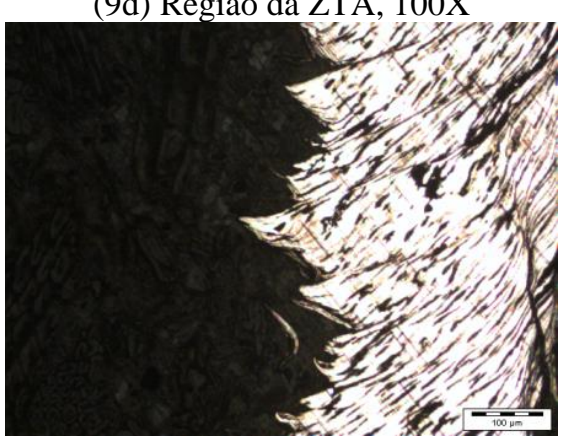

(9b) Região da ZTA, 500X

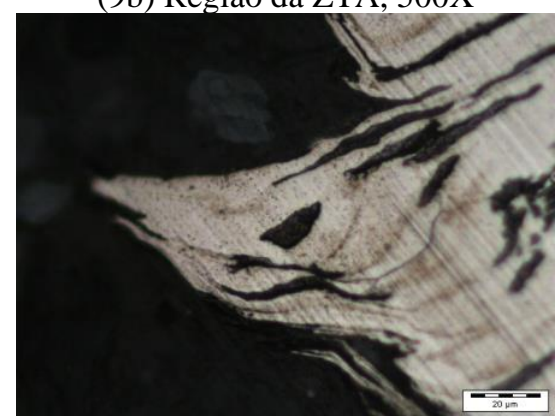

(9e) Região do metal de base $200 \mathrm{X}$

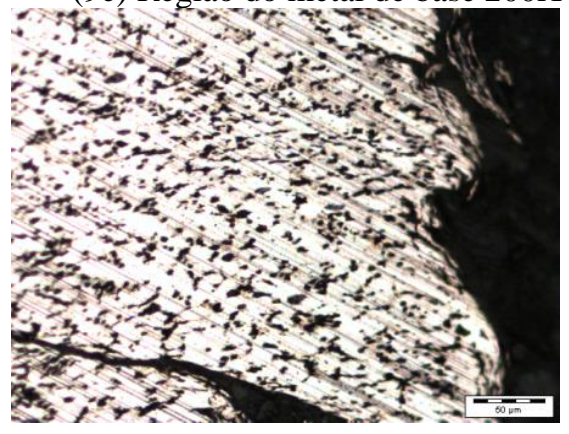

Fonte: Autores (2021). (9c) Região do metal de base 500X

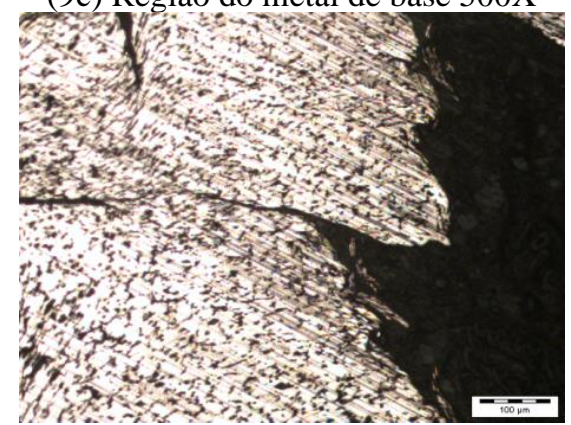

(9f) Região da ZTA, 200X

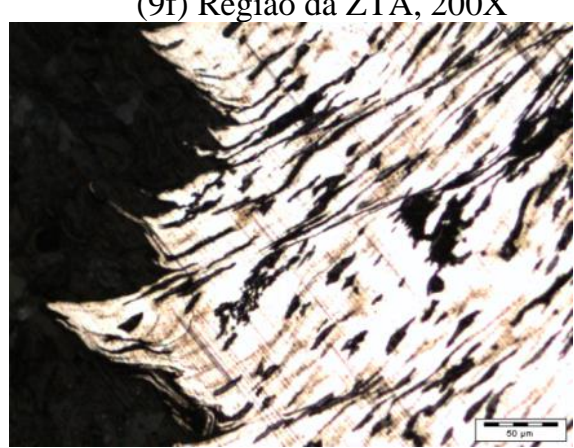

O ensaio de dureza foi realizada em 5 (cinco) pontos em cada área metal base e na ZTA, Tabela 2.

Tabela 2. Ensaio de Dureza - HRC nas regiões do metal base e zona termicamente afetada.

\begin{tabular}{ccccccc}
\hline Região & Ponto 1 & Ponto 2 & Ponto 3 & Ponto 4 & Ponto 5 & Média \\
\hline Metal base & $24.3 \mathrm{HRC}$ & $29.3 \mathrm{HRC}$ & $20.9 \mathrm{HRC}$ & $27 \mathrm{HRC}$ & $24 \mathrm{HRC}$ & $24.8 \mathrm{HRC}$ \\
ZTA & $43.7 \mathrm{HRC}$ & $41.3 \mathrm{HRC}$ & $42.5 \mathrm{HRC}$ & $42 \mathrm{HRC}$ & $43.4 \mathrm{HRC}$ & $42.6 \mathrm{HRC}$ \\
\hline
\end{tabular}

Fonte: Autores (2021).

Os valores da dureza na região do metal base demostra baixa variabilidade e é evidenciado pelo controle do processo de soldagem. Na região termicamente afetada apresenta o aumento dos valores de dureza, devido ao comportamento microestrutural, mediada pela morfologia e topografia dos cavacos.

\section{Considerações Finais}

O processo de soldagem para recuperação dos cilindros de laminação por análise de cavacos do processo de torneamento conclui-se de certa forma o esperado com os resultados apresentados. Neste sentido, a soldagem do cilindro de 
laminação com o processo SMAW, conclui que por meio das análises laboratoriais por microscopia óptica e eletrônica que, a ZTA apresentou uma mudança transitória de ferro fundido coquilhado ou branco para ferro fundido cinzento pelo comportamento do calor envolvido e pelos elementos de ligas tanto da peça quanto do eletrodo.

Observou no comportamento dos cavacos embutidos para as análises, a mudança tanto da forma geométrica quanto ao tipo somada as mudanças de microestruturas no cavaco do metal de base, componentes grafita mais esféricos do que o cavaco das regiões de ZTA, isto se deve ao fato de uma grafita esféricos que ajuda nos movimentos das discordâncias do material, que apesar de elástico ter comportamento de materiais deformáveis.

Contudo por meio dos parâmetros de qualidade da área de usinagem as análises por meio dos cavacos transformaram um aliado importante nos processos de soldagem, já que para se provar qualquer descontinuidade nestes processos de fusão e corte são feitas outras análises por ensaios não destrutíveis, destrutíveis e análises metalográficas macro e microscópica para confirmar tal processo de soldagem.

Com o ensaio de dureza do MB e ZTA, pode observar que a região da ZTA apresentou uma dureza maior do que a dureza do MB, devido ao acúmulo de tensões e fases transitórias causados pela soldagem. Levando em consideração os parâmetros de reparo nos cilindros de laminação, essa diferença de dureza não influencia diretamente nas propriedades mecânicas e na utilização do cilindro.

Evidenciou-se que na soldagem dos cilindros de laminação como o processo de reparo foi muito eficaz, além de facilitar o processo e diminuir custos para a empresa. Ressaltou-se que não foi possível revelar os parâmetros de soldagem e parâmetros de corte, tanto como desgaste de ferramentas, uso ou não de fluido de corte que segue como sigilo empresarial.

Para melhor dimensionar os resultados das análises da morfologia da grafita, o próximo passo será uma análise quantitativa e qualitativa das grafitas por meio de processamento de imagens, verificação da composição química tanto dos elementos contidos nos eletrodos com elementos adicionados no processo de nodularização da grafita, que devem ser fornecidos pelo fabricante, além dos estudos de desgaste de ferramentas utilizando conceito de Taylor para "vida de ferramenta".

\section{Referências}

Askeland, D. R.; Phulé, P. P. (2008). Ciência e engenharia dos materiais. [S.1.]: Cengage Learning.

Andrade, R, B. (2009). Parâmetros térmicos e estruturais em ferros fundidos cinzentos e nodular solidificados em moldes de areia e unidirecionalmente. São Paulo.

Barros, A. J. S. \& Lehfeld, N. A. S. (2000). Fundamentos de Metodologia: Um Guia para a Iniciação Científica. 2 Ed. São Paulo: Makron Books.

Chiaverini, V. (1990). Aços e ferros fundidos. $6^{\mathrm{a}}$ ed., São Paulo: Associação Brasileira de Metalurgia e Materiais, 576p.

Cojocaru, A. M., Riposan \& L., Satan, S. (2019). Solidification Influence of Inoculation effects in ductile Cast Irons by Thermal Analysis. Journal of Thermal Analysis and Calorimetry; Akadfoimiai Kiadó, Budapest.

Dawson, S. (2001). Controlling the Production of Compacted Graphite Iron. SinterCast, Inc, Auburn Hills, Michigan.

Diniz, A.E. Marcem, F. C \& Coppini, N.L. (2013). Tecnologia da Usinagem dos Metais. Editora art liber, São Paulo.

Gil, Antônio Carlos. (1999). Métodos e técnicas de pesquisa social. 5. ed. São Paulo: Atlas.

Guesser, W. L. (2009). Propriedades mecânicas dos ferros fundidos. $1^{\text {a }}$ Ed. São Paulo: Blücher.

Guesser, W., Schroeder \& T., Dawson, S. (2001). Production Experience With Compacted Graphite Iron Automotive Components. AFS Transactions, American Foundry Society, Des Plaines, USA: Paper 01-071, p.1-11.

Guesser, W., Masiero \& I., Cabezas, C. (2005). Thermal Conductivity of Gray Iron and Compacted Graphite Iron Used for Cylinder Heads. Revista Matéria, vol 10, n. 2, Junho, p 265-272.

Heisser, C. \& Sturm, J.C. (2003). Casting Process Simulation of Compacted Graphite Iron. AFS Transactions, American Foundry Society, Des Plaines, USA: Paper 03-025, p.1-8. 
Research, Society and Development, v. 11, n. 3, e20011326091, 2022

(CC BY 4.0) | ISSN 2525-3409 | DOI: http://dx.doi.org/10.33448/rsd-v11i3.26091

Klink, U. \& Flores, G. (2001). O Uso da Grafita Vermicular em Cilindros Fundidos. Revista Máquinas e Metais, Fevereiro. p 38-47.

Nunan, D. (1997). Research methods in language learning. Cambridge: Cambridge University Press.

Li, Yongjian, Dong, Shiyun, Yan, Shixing, Liu, Xiaoting, He \& Peng, Xu, Binshi. (2018). Surface Remanufacturing of Ductile Cast Iron by Laser Cladding Ni-Cu Alloy Coatings. Surface \& Coatings Technology 347, 20-28.

Ramon, O, B, S. Pedro H. C. P. Livya V. M. O. \& Renann P. G. (2020). Análise Metalográfica da Formação de Cavaco do Aço SAE 1020 em um Processo de Torneamento por Comando Numérico Computadorizado. Revista SODEBRAS - Volume 15 N $^{\circ} 175$ - JULHO/ 2020.

Saad, F. (2012). Inspeção de peças em fundição. http://www.manutencaoesuprimentos.com.br/conteudo/6331-inspecao-de-pecas-emfundicao.

Serantoni, C. R. (2014). Cilindros de Laminação. http://www.moodle.stoa.usp.br/mod/resource/view.php?id=42612.

Teles, J. M. (2007). Torneamento de Ferro Fundido Nodular Ferritizado com Nióbio Utilizando Ferramentas de Metal Duro. Dissertação de Mestrado do Programa de Pós-Graduação em Engenharia Mecânica. Universidade Federal de Itajubá.

Tooptong, S. Park, K. \& Kwon, P. (2018). A Comparative Investigation on Flank Wear When Turning Three Cast Irons. Tribology International 120, 127139. 